\title{
Health Care Providers' Perceptions of the Vulnerability of Persons with Disabilities: Sociological Frameworks and Empirical Analyses
}

\author{
Patricia B. Mullan, Ph.D., ${ }^{1,3}$ and Sandra S. Cole, Ph.D. ${ }^{2}$
}

In this study, we explored health care providers' perceptions about their professional responsibility for persons with disabilities. We examined the providers' perceptions of the vulnerability of persons with disabilities to sexual exploitation. We also elicited the professionals' assumptions about the consequences of such exploitation to the persons with disability and the professionals working with them. Our analyses indicated that these professionals perceived that different categories of disability pose different risk of sexual exploitation. Populations with forms of cognitive impairment were considered most vulnerable. In terms of professional responsibility for the care of persons who might have experienced sexual exploitation, respondents reported least confidence in their ability to detect instances of exploitation. In contrast, respondents expressed greater confidence in their ability to report and conduct follow-up of abuse. The professionals anticipated providing emotional support to persons who experienced exploitation. We discuss the study's implications for training and policy formation.

KEY WORDS: disability; attitudes of health care personnel; risk assessment.

\section{INTRODUCTION}

This paper considers sociological concepts relevant to the study of health care providers' attitudes toward their professional responsibilities for persons

'College of Human Medicine, Michigan State University, East Lansing, Michigan.

${ }^{2}$ University of Michigan Medical Center, Ann Arbor, Michigan.

${ }^{3}$ Correspondence should be directed to Patricia B. Mullan, Michigan State University, College of Human Medicine, A 214 East Fee Hall, East Lansing, Michigan 48824. 
with disabilities. We use these concepts to frame the report of our empirical research, exploring health care providers' perceptions of 1) the vulnerability of persons with disabilities to sexual exploitation and 2) the consequences-for both the person with disability and the professional working with them-of such exploitation.

\section{SOCIOLOGICAL FRAMEWORKS FOR STUDYING PERCEPTIONS OF DISABILITY}

Health care polices in the United States resemble Moiré light patterns, in which the arrangement of light and dark shift with each new perspective. Definitions of what constitutes problems and their solutions change, particularly in policies directing care of vulnerable populations. Light and Pillemer(1) note such shifts discerned in meta-analyses of studies on related topics over time. For example, one can trace historical fluctuations in federal research seeking to document problems engendered in children "deprived of" or "doomed to" daycare.

Efforts directed toward identifying likely problems and preferred solutions to the care of populations with disabilities reflect more general trends in determining institutions(2) most appropriate for solving medical and social problems. In the care of populations with disabilities, attention centers on the institutions of the family and medicine. The dialogue between familial and professional worlds occurs as a dialectic, in which the dynamics and functions associated with one institution are presented as complementing or supplementing those associated with the other.

Until the emergence of large urban areas in the United States, the care needs of persons with disability were treated as the responsibility of the family.(3) Critics intent on improving care challenged this arrangement. Dorothea Dix presented strident criticism of the family's treatment of the vulnerable. Her work in mobilizing concern for the mentally disabled beseeched audiences to deliver the vulnerable from those who placed them in "cages, closets, cellars, stalls . . . penned, chained, naked, beaten with rods, and lashed into obedience."(4) Such stories of abuse evoke dismal fears for the potential of human relationships, of families and communities who reject most cruelly those they perceive as disabled or deformed, from the legacy of hate in the Greek myths of Hera, seeing her son Vulcan as weak and ugly, casting him down from Mount Olympus.(5)

A kinder, gentler image of the family and medicine emerges in Renée Fox's description of the movement toward "medicalization"-i.e., defining a problem as medical and, thus, to be treated by the medical professional.(6) Fox portrays the tendency to delegate responsibility to medicine as a warranted 
sympathetic response to the family. This explanation attributes best intentions to both medicine and the family, but recognizes that, at this point in history, the institution of medicine is considered better able to define and provide resources for many difficult problems. For example, defining alcoholism as a disease expanded the repertoire of social responses from the purview of the police and courts to psychological and medical treatment covered by insurance. "Medicalization" also augments the professional status and autonomy of medical practitioners.

Concerns about the effect of according this responsibility to the institution of medicine have centered on potentially adverse consequences of imposing impersonal routines of care on vulnerable populations. Goffman explicates these concepts, describing both the power of "total institutions"- from jails to intensive care units-in which every aspect of an inmates' life is controlled bureaucratically, and the vulnerability of "stigmatized" populations.

Goffman stresses that persons with disabilities share problems attendant to being stigmatized, i.e., they have some characteristic that is deeply discrediting to their personal identities. This characteristic leads to a "spoiled identity, and renders the individual suspect in moral character." Goffman explicitly considers the social consequences that those faced with the problems of mental illness and physical defects ("abominations of the body") share with others bearing stigmatizing conditions: "an individual who might have been received easily in ordinary social intercourse possesses a trait that can obtrude itself upon attention and turn those of us whom he meets away from him, breaking the claim that his other attributes have on us. He possesses a stigma, an undesired differentness from what we had anticipated."(7) This "differentness" can so define individuals that they cease to expect to be treated as persons. For example, individuals using wheelchairs reported that "people only see the chair, never me." $(8)$

Were concerns about alienation not sufficient to indicate the presence of a problem, we now confront evidence of active exploitation. The study of sexual exploitation of persons with disabilities has undergone several critical phases. Initial writings described individual or clusters of case studies documenting incidences of abuse of persons with particular disabilities.(9) This testimony has been critical in mobilizing concern and allocation of resources to address this problem. Subsequent work has described counselling and prevention programs that are or should be available to persons with particular disabilities.(10) One objective of these programs has been to increase the attention of individual health care workers and service agencies to their efforts in detecting and referring for treatment persons within particular populations who might have been abused. The implicit assumption of much of this work has been that the individual health care worker has the knowledge, attitude, and skills to protect the persons with disabilities from abuse.

Formulating these programs entails maintaining the delicate balance be- 
tween documenting the severity of need, while refraining from reifying stereotypes surrounding sexual exploitation. These stereotypes render persons with disabilities equivalent to a helpless population. Vulnerability to sexual exploitation seems yet one more plague besetting an affected population.

In this scenario, the individual with disability is ever more dependent on the selfless health care professional as advocate. Writing in the Hastings Center Report, Will champions for dependence on good will, rather than greater legislation, as the most effective means for protecting persons with disabilities:"The multiplication of rights-legally enforceable claims on the attention, actions, and resources of others - can carry us only so far. Improvements for the handicapped depend primarily on improving the attitudes of the nonhandicapped majority through appeals to conscience and good will."(11) The attribution of seemingly magical power to health care providers' good intentions crosses political boundaries. For example, in examining the course of readjustment among Israeli war veterans, Ben-Sira attributed veterans' maladjustment, in part, to the rehabilitants' perception that their therapists could be discerned as having latent professional goals for successful outcome. Ben-Sira concluded that only the rehabilitants fortunate enough to work with professionals who demonstrated sincerely humane behavior, free from personal aspirations for their patients, could be expected to achieve therapeutic outcomes.(12)

The most disturbing flaw in this picture is the increasing evidence of abuse perpetrated by the very people-including health care workers-upon whom the person with disability is posited as dependent.(13) Caricatures of abusers portray loathsome strangers. To the extent that attention remains on preventing or detecting the actions of abberrant individuals, our theoretical accounts for understanding the more subtle interplay of perceptions, actions, and professional responsibility in response to vulnerability remain unillumined.(13-16).

What are the attitudes of health care professionals about the vulnerability of and their responsibility toward persons with disabilities? What is the impact of moving the care of stigmatized populations to medical professionals? Given that clinicians rarely raise inquiry about sexual health, sexual activity, and abuse in their care of the general population,(18) what frameworks of study might illumine the contingencies operating on health care professionals' approach to the exploitation of persons with disability?

Mechanic has formulated the concept of the "social context of practice"i.e., the premise that the behavior of both patients and health professionals is molded, in part, by their particular culture, prior training, and the climate of the helping situation. This thesis provides a heuristic for approaching "the participants as active parties, who are not simply reactors to social and situational demands, but who make efforts to shape their settings and work to reduce uncertainty and increase their personal rewards."(19) From this perspective, we can explore the behavioral contingencies operating within the clinical environ- 
ment and, in particular, how the general strategy of controlling uncertainty might affect the professionals' perception of and response to persons with disability.

As Fox explains, training for uncertainty constitutes a central task in becoming a health care professional.(20) Mechanic illustrates this from the perspective of the health care student. The health care student holds ideal expectations that are unrealistic in terms of such real constraints as the breadth of knowledge to be mastered, time available, and competing academic and social expectations. Students must, then, develop some strategy of negotiating among these various demands. As students progress, they learn to live with uncertainties arising from the state of medical knowledge, their own mastery, and the ambiguities of clinical practice.(18)

Light developed a taxonomy for categorizing the kinds of uncertainties and the techniques that health care professionals adopt for coping with uncertainty. The kinds of uncertainty facing health care professionals include uncertainty of professional knowledge, diagnosis, procedure and treatment, collegial relations, and client response. Techniques for controlling uncertainty include specializing, adopting a "school" of professional work, and deferring to clinical experience.(21)

Collectively, the organization of professional fields of sexology and rehabilitation medicine exemplify such attempts to reduce uncertainty and attain professional autonomy by carefully defining fields of expertise.(22-23) As Albrecht notes, the recent emergence of "disability"-as an entity in national census counts and as a field of formal medical expertise-places special burdens on the health care professional dealing with problems not readily addressed in the medical model or observed in hospital settings.(24) Practitioners within medical professions learn to avoid uncertainty occasioned by limits within their own knowledge, or assumed detrimental responses of their patients or colleagues.

Reluctance to engage in practices perceived as unwarranted or ineffective is true for those at the "lower," as well as the "upper," levels of the medical hierarchy.(25) For example, a study of an institution for the severely retarded found that the staff often resisted proposed "improvements" in care routines. In explaining their reluctance, the attendants cited the impracticality of the proposed programs, as well as the increased burden that implementation would place on them. The study authors concede that: "perhaps attendants' reactions constitute realistic adjustments to the truth of these facilities. To offer programming as a remedy to a system that by its very nature isolates, desocializes, and dehumanizes, reminds us of Marie Antoinette's remark when informed that her subjects were starving - that they had no bread. Her response was: 'let them eat cake." The authors echo this refrain in their study title as "let them eat programs."(26) 


\section{EMPIRICAL STUDY OF HEALTH CARE PROVIDERS' PERCEPTIONS}

Our empirical study of professionals' perceptions of the vulnerability of persons with disability drew upon theoretical developments and empirical research on the perception of and reaction to stigma and the social context of health care professionals. $(6,21,25-27)$ In this study, we explored the social context in which the health care worker cares for persons who might have been sexually exploited. We attempted to ground the inquiry of health care workers' perception of vulnerability to their professional preparation, contact with, and responsibilities for populations with different disabilities. We endeavored to disentangle the study from general attitudes toward disability by making explicit questions of both differential risk posed to persons with particular kinds of disability and the realm of responsibility attendant on the professional. In addition, we explored health care workers' perceptions of the possible consequences in caring for a person with a disability who has been sexually exploited.

The specific research questions posed in this study included:

1. Do the persons who are concerned with the care of populations with disability consider themselves trained in sexual health and sexual abuse prevention?

2. How vulnerable to sexual exploitation do these professionals perceive different populations of persons with disabilities?

3. How confident are these professionals in detecting, reporting, and providing follow-up care to persons with disabilities who experience sexual exploitation?

4. What do health care professionals consider the best and worst consequences of dealing with sexual exploitation that the patient and the professional might encounter?

\section{METHOD}

We conducted this research in the context of a conference addressing the sexual exploitation of persons with disabilities. The second author (Dr. Sandra Cole) organized this conference as an attempt to define for health care professionals the issues that arise in dealing with the sexual exploitation of persons with disabilities. This conference brought together faculty from the United States and Canada to discuss issues and develop strategies for preventing sexual exploitation of persons with disabilities. The conference format included workshops and seminars, with a keynote speech setting the tone for each day. A 
series of independent workshops and small group seminars were presented on a broad range of topics. These sessions were designed to:

increase awareness of the extent of sexual abuse;

identify and examine methods of prevention;

provide strategies for developing curricula, intervention techniques, and therapy and counseling services;

share information about organizational, training, and bibliographic resources; and present legislative efforts and results.

The conference organizers selected a panel of experienced faculty from Canada and the United States to prepare and deliver the conference workshops. This faculty represented diverse academic fields and professional and consumer organizations-including education, psychology, sexology, child and family studies, law enforcement, social work, sex education, counselling, and therapy, independent living centers, government advocacy groups, theater, residential institutions, national prevention programs, treatment centers, parent advocacy groups, service agencies and facilities-encompassed in the topic of abuse of persons with disability.

As is often the case in interdisciplinary study, shared meanings among researchers operating from different disciplines must actively be established.(29) A secondary agenda for this conference, then, was to establish a forum for communication and interdisciplinary approaches among the highly trained, experienced, and committed professionals the faculty represented.

All conference participants were asked to complete the survey research instrument. Conference participants reported the populations with disability included in their professional environment, the setting in which they discharge their professional responsibilities, and their training in sexual health and sexual abuse prevention. Participants were also asked to consider how vulnerable they considered specific populations of persons with disabilities were to sexual exploitation, how frequently they encountered a person with disability whom they considered might have been sexually exploited, and how likely they considered that the persons were aware they had been exploited. In addition, participants also assessed their confidence in detecting, reporting, and providing follow-up care to persons with disabilities who have been sexually exploited. Questions about participants' confidence in reporting instances of abuse included situations in which the person implicated is a member of the patient's family and those in which the implicated abuser is a health care professional.

The final section of the survey contained a series of open-ended questions, asking participants to identify what would be the best and worst possible consequences to the person with a disability who reports being sexually exploited; the best and worst possible consequences to the health care professional helping 
Fig. 1. Disability populations present in care environment of providers.

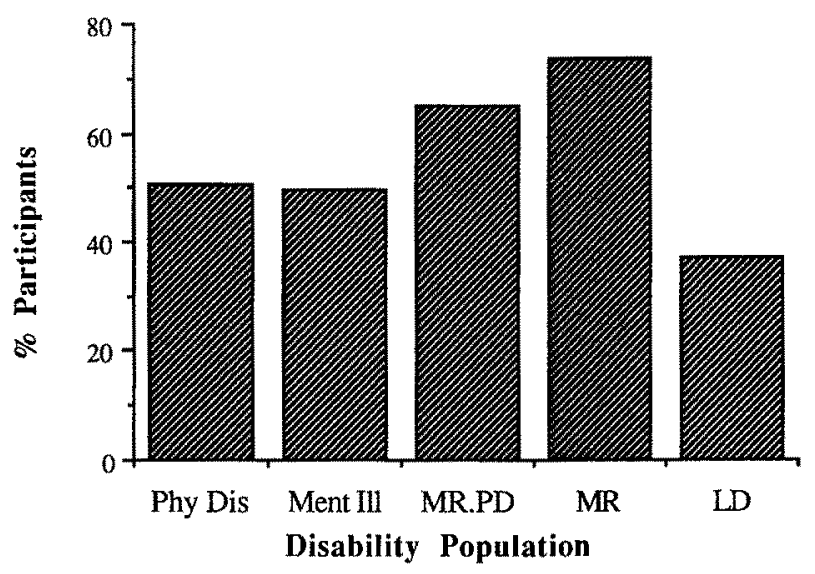

the person with a disability who reported being sexually exploited; and the identification and availability of the resources they would like to draw on in helping a person with a disability who reported being sexually exploited.

The explanation accompanying this survey stressed that the intent of the survey was to identify current strengths and concerns for the planning of future training and support efforts; we emphasized that the survey was not intended to evaluate individuals.

Data analyses included calculating the frequency distribution of the kinds of disability present in the populations included in the care responsibility of the conference attenders, the level of training in sexual health and abuse prevention, the health care providers' perception of the vulnerability of persons to sexual exploitation, and the health care providers' confidence in detecting, reporting, and conducting follow-up of incidences of sexual exploitations. We used Kendall's coefficient of congruence to assess the consistency of the relative rating of items, and repeated measures analysis of variance to examine the magnitude of the differences among the mean values representing participants' perceptions of the vulnerability of different patient populations and the participants' confidence in discharging their professional responsibilities for detecting, reporting, and providing follow-up of instances of abuse. We used Scheffé post hoc tests to identify the contrasts sufficiently different to account for overall differences among the means compared in analysis of variance.

We used analytic induction methods to analyze the participants' responses to the open-ended questions describing perceived "best" and "worst" outcomes. The iterative process of analytic induction involves assessing the adequacy of categories identified in the analysis of initial cases through the examination of 
Fig. 2. Conference participants' self-reported formal training in sexual health and abuse prevention.

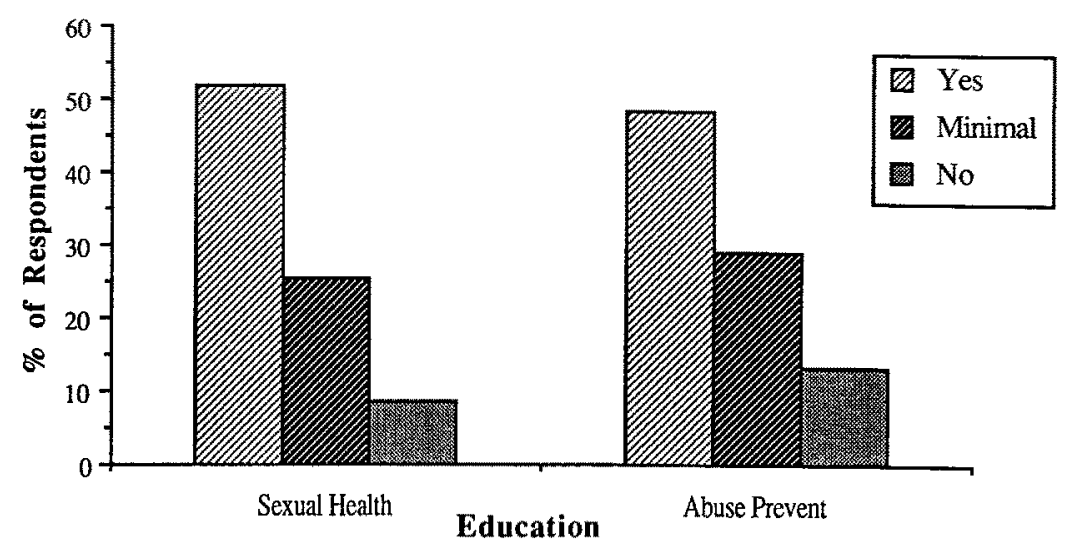

subsequent cases ("negative instances") that are consciously selected to challenge or refine the originally posited pattern of responses, until all the responses are incorporated into the category system.(30)

\section{RESULTS}

Figure 1 illustrates the conference participants' description of the populations with disability present in their professional environment. The populations of persons with particular disabilities were present in the following relative order: mental retardation; combined mental retardation and physical disability; physical disability; mental illness; learning disability; other disabilities (deafness, visual impairment). The challenge confronting these professionals is evident in the percentage of respondents whose professional milieu include persons with diverse kinds of disability. The care environment of the majority of respondents included responsibility for at least two major categories of persons with disability; half $(53.0 \%)$ of the respondents reported responsibility in environments with persons representing three or more categories of disability.

The overwhelming majority of respondents described themselves as working in community organizations, governmental (city, state, or federal) agencies, social units representing families, foster homes, and advocacy centers. A relatively smaller percentage of people represented hospital (17\%) and clinic (13\%) settings.

Figure 2 contains the conference participants' description of their formal training in sexual health and sexual abuse prevention education. Approximately 
Fig. 3. Mean perceived vulnerability of persons with disabilities to sexual exploitation.

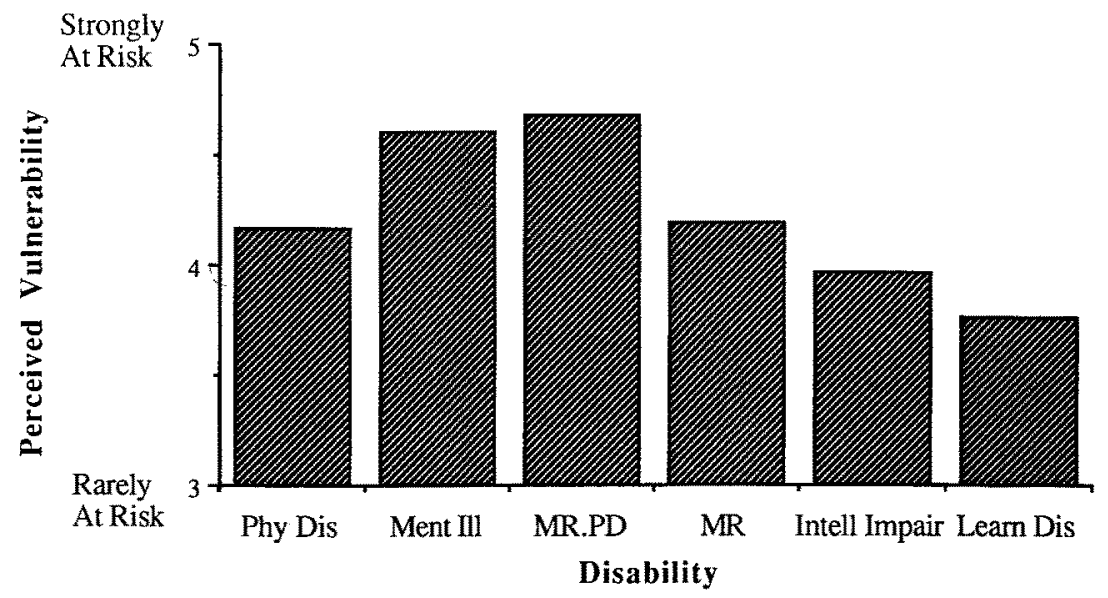

two-fifths $(39.8 \%)$ of the respondents noted that they had no training in sexual health; a similar proportion (38.5\%) of respondents reported that they had no training in sexual abuse prevention. Approximately half (51.8\%) of the respondents indicated that they had received training in sexual health; a comparable proportion (48.2\%) of respondents indicated that they had training in sexual abuse prevention. Survey respondents, however, were very critical in reporting their training in sexual health and sexual abuse prevention. Although the survey instrument presented the question about person's training in a closed-ended format that would be expected to elicit a "yes" or "no" response, many of the respondents who noted that they had training in sexual health or sexual abuse prevention qualified their own self-reports. Respondents added that their training was "minimal," "informal," or "outdated" in sexual health $(8.4 \%)$ and sexual abuse prevention (13.3\%).

Figure 3 illustrates the participants' mean perception of vulnerability to abuse among populations with defined disabilities. It should be noted that the origin in this graphical representation begins at the midpoint (" 3 ") in the scale, for all respondents reported that all populations bore some extent of vulnerability to sexual exploitation. The statistical analysis of these responses transformed the data to derive the implied "rank order" of the vulnerability of different populations. The ranking of populations considered "most vulnerable" to "least vulnerable" were: combined mental retardation and physical disability; mentally ill; physically disabled; mentally retarded; intellectually impaired; and learning disabled. The consistency of this sequence of ranking was statistically significant $\left(\chi^{2}=204, \mathrm{p}<.001\right)$.

We also examined perceptions of vulnerability in terms of the distribution 
Fig. 4. Distribution of vulnerability assessments attributed to persons with disabilities.

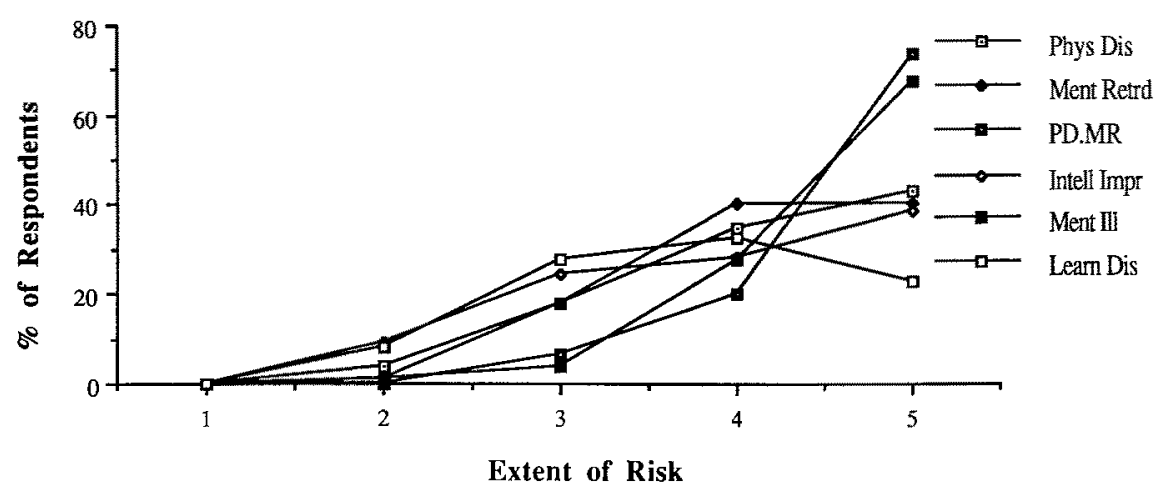

among assessments of relative vulnerability confronting populations with disabilities. We first examined judgments of risk accorded independently to each category of disability (e.g., the risk assessments expressed in the ratings considering the risk posed to those physically disabled, independent of how or if those raters judged other categories). Common to these ratings was the assumption that all persons with disability bore some risk of exploitation. To control for potential differences in the rating introduced by some of the respondents responding selectively to the risk assessment task, (i.e., they rated some, but not all, of the disability categories), we examined the distribution of ratings recorded by respondents who rated all categories of defined disability. As illustrated in Figure 4, this distribution illustrates that the majority of respondents consider patient populations with forms of cognitive impairment-including mental illness, combined physical disability and mental retardation and mental retardation-as confronting the greatest extent of risk. The risk attribution to physical disability, in contrast, is distributed more diffusely; i.e., there is less consensus about the extent of risk posed to the physically disabled. Fewer respondents considered persons with learning disability as confronting greater degrees of risk. The populations considered "most vulnerable" were persons with long term cognitive disabilities: i.e., combined mental retardation and physical disability, mental illness, and mental retardation. In contrast to other populations with disabilities, learning disabilities seemed to the conference participants to pose less extreme measures of risk of abuse.

In the results of one way analysis of variance comparing the magnitude of perceived vulnerability as a function of the level of the respondents' training in sexual health, only one distinction emerged; respondents who reported training in sexual health (by responding "minimal" or "yes") accorded greater vulnerability 
Fig. 5. Participants' report of probability of encountering persons with disabilities

a) Who've been exploited b) Are aware they've been exploited.

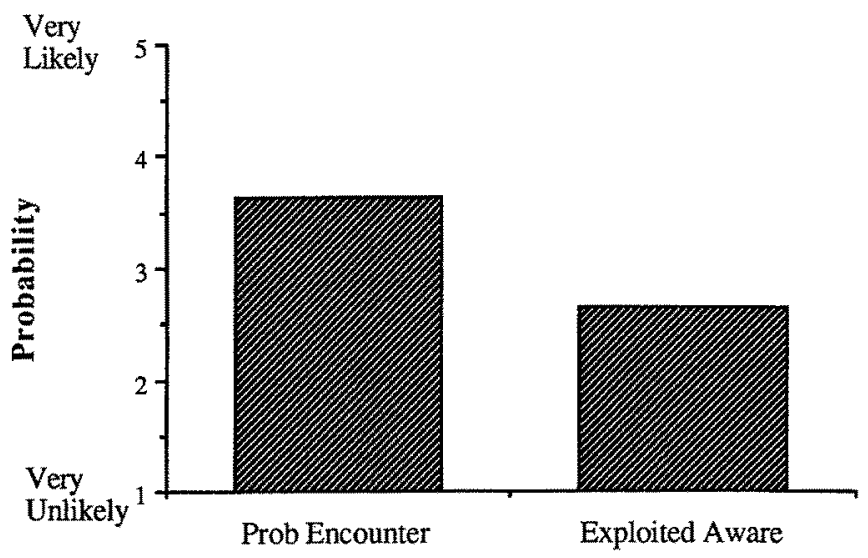

to persons with intellectual impairment than did respondents who reported no training in sexual health. In contrast, the absolute magnitude of perceived vulnerability varied as a function of training in sexual abuse prevention. For example, respondents with training accorded greater vulnerability to populations with combined physical disability and mental retardation $(\mathrm{F}=6.9, p<.001)$ and intellectual impairment $(31)(\mathrm{F}=8.8, p<.001)$ than did respondents without training. Training in sexual abuse prevention did not affect the vulnerability perceived as confronting persons with mental retardation or learning disability.

An additional set of analyses considered whether the assessment of perceived vulnerability varied among people with professional responsibility for persons with that category of disability. The findings of these analyses indicated that persons in environments with professional responsibility for persons with physically disability perceived that population and the population with combined physical disability and mental retardation to be more at risk than persons whose professional environment did not include persons with physical disability.

Figure 5 illustrates the responses of the participants to two questions: 1) how often they considered they encountered a person with a disability who had been sexually abused; and 2) whether or not they thought the person who had been abused was aware of the abuse. A majority (53.7\%) of the respondents consider they very frequently encountered persons with disability who had been exploited. Relatively few respondents $(3.7 \%)$ considered that they never encountered persons with disability who had been exploited. Almost half of the respondents $(47.5 \%)$ thought that the person with disability who had been exploited might not be aware they had been exploited. 
Fig. 6. Confidence in caring for persons with disability who have been exploited.

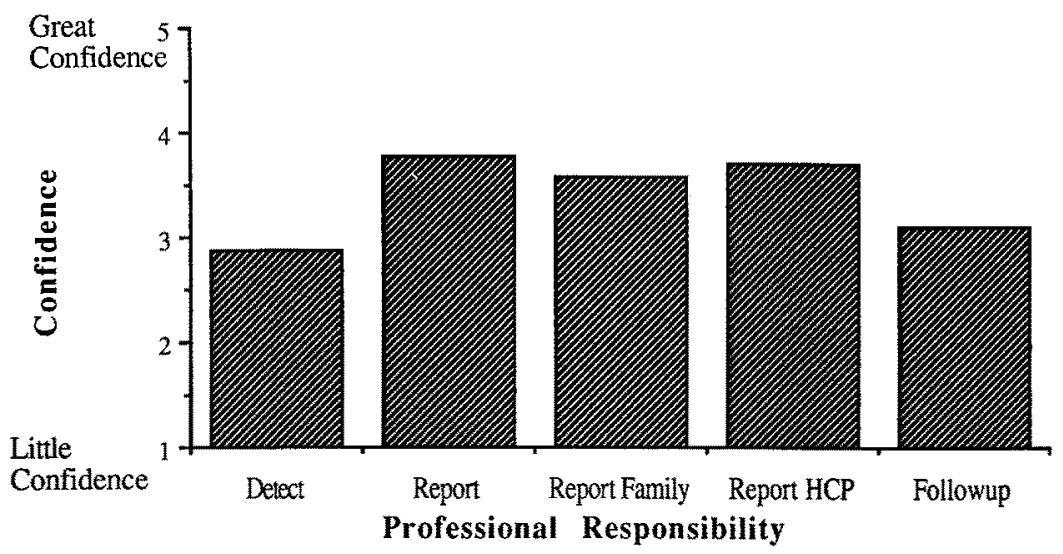

In keeping with the theme of the conference, the difficulty posed to individuals in discharging their professional care responsibilities was assessed. Figure 6 illustrates the mean confidence reports of the participants in detecting, reporting, and providing follow-up to persons with disability who had been exploited. The statistical analysis of these responses transformed the data to derive the implied "rank order" of the participants' relative confidence in discharging their professional care responsibilities. The responsibilities for which respondents reported "great confidence" to "little confidence" were: reporting instances of exploitation; reporting instances in which a health care professional is the perpetrator; reporting cases in which a family member is the perpetrator; providing follow-up to cases of exploitation; and detecting instances of exploitation. The consistency of these rankings was statistically significant $\left(\chi^{2}=143\right.$, $p<.001)$. Respondents reported least confidence in detecting instances of exploitation. Subsequent analyses indicated that, when comparing the magnitude of the rating a respondent gave to exploitation involving a health professional offender to those involving a family member offender, the respondent reported more confidence in ability to report instances involving health professionals.

The results of analytic induction indicated that participants' perspectives of the "best" and "worst" outcomes of reporting abuse and the "desired" and "available" resources for working with instances of abuse could be categorized as 1) affective (sympathetic and empathetic responses and those concerned with the credibility of the patient and the professional); 2) behavioral (providing immediate coping or medical redress for the patient's injury; and 3) social (involving - or challenging - the larger social, political, or legal environment).

The distribution of these responses is illustrated in Table 1. The overwhelming proportion of health care professionals' responses described consequences only in terms of impact upon the feelings or perceived credibility of 
Table I. Projected Scenario: Best Outcome for Patient

Response

Category

Affective

Behavioral

Social

\section{Examples}

"Being believed" "Being listened to" "To be given credence" "To have the confidence to be able to report exploitation-to know they are being exploited" "Finally getting support" "Enhanced self-esteem-'I helped myself and other" "Mental health professionals will be supportive and empowering" "Gets attention and care from the right people"

"The person is trained in self-defense. The setting is corrected so the offender is removed" "The offender being treated fairly and the victim learning to avoid another similar situation" "Person is provided with protection from further immediate abuse and provided with treatment"

"Offender gets jailed" "The rules are made more stringent so the opportunity doesn't occur"

Projected Scenario: Worst Outcome for Patient

Response

Category

Affective "Not being believed" "Not to be heard truly i.e., no follow-up on report-or not to be found credible" "Being exploited because of the report. In reality, abused by the system. We have very few options for these problems for the people involved in these problems." "To not be believed or to be made to feel that they have done something wrong" "The victim is seen as the perpetrator or guilty of seducing the perpetrator" "Blamed and punished for reporting" "Familial rejection" "Going through the legal raped reporting procedure without any help being given to the victim" "Depression and guilt feelings" "Loss of family contact and/or visit"

Behavioral "Contracting AIDS from the perpetrator" "Physical retaliation from the perpetrator" "Removed from group/home and ostracized, implicated person not found guilty"

Projected Scenario: Best Outcome for Health Care Professional

Response

Category

Affective "Reassuring the person" "The individual had been assisted, was 'better off' by the contact" "Not to be able to support person's credibility" "Being able to assist the client through the traumatic experience and going on with their life" "Victim gets help" "To facilitate the support that enables a person to heal and regain control" "Learning from the experience and mishap. Good deed to person with disability without recognition" "Seeing that the person assimilates what has happened, learn that the victim was not at fault" "The professionals are supported in their work" "Support" "To prove the victim has been sexually exploited" "being aware that such a situation can exist"

Behavioral "Network to other informed professionals, case consultation, systems support" "Interagency communication and cooperation leading to a truly helpful, long-term, positive intervention" "Resolving the abusive situation while providing the victim with the least restrictive living arrangement" "Supportive network through intervention and counseling" 
Table I. (Continued)

Projected Scenario: Worst Outcome for Health Care Professional

Response

Category

Affective "To be placed in a position of not being able to help" "Not being believedwasted time" "Frustration and inconveniences" "Not taken seriously, and other professionals thinking the client is lying" "To be accused of headhunting" "Other professionals who should be supportive, refuse or are unable to be" "Lose their credibility" "Cross-examination by a skilled defense attroney, in front of an unsympathetic judge" "Losing their professional credibility" "To not be believed. That your view of the situation is invalidated and you are blacklisted by other professionals as a quack"

Behavioral "Physical attack" "Fired, mocked, discounted" "Fired for making waves by not doing job description" "Administratively ordered not to continue assistance" "Retaliation from abuser" "Being sued by the victim's family"

Social "Lawsuit" "Professional is sued for false reporting and loses license"

"Liability issues, malpractice suits"

Projected Scenario: Resources Desired

Response

Category

Affective "My own empathy and inner strength" "Compassionate health care providers, social workers, clergy and family members"

Existing

Social

Institutions

"Local agency" "Legal assistance in preparing a case and collecting admissible evidence" "Existing victim support and perpetrator support groups" "Techniques in interviewing, especially the mentally retarded" "Hospital and some follow-up services of some kind" "Sex abuse clinic, mental health clinics" "Sexual assault crisis center" "Crisis intervention, therapy" "Network of consultants I can consult" "Social services, courts" "Family, home staff, counselor, and legal professions" "Peer support group and training" "Shelters" "I would need the assistance of the agencies that deal with the disabled on a regular basis"

the patient. This response pattern occurred across imagined "best" and "worst" outcomes for both the professional and the patient, and across the kinds of resources upon which the professional could or would like to draw. The most frequent types of action following the report of abuse involved the credibility and reassurance of the patient (on the belief that the patient would not be believed), and, indirectly, the imputed reflection upon the professional credibility of the health care provider. Very few of the responses addressed the issue of insuring physical safety of the client and health care worker. While existing programs involving the judicial and protective services agencies were cited among resources available, less than $1 \%$ of respondents considered that the potential impact of persons reporting abuse or their actions as health care pro- 
fessionals in mitigating the abuse could or should affect the structure or delivery of these programs.

\section{DISCUSSION}

Existing studies have examined attitudes toward persons with particular disabilities, and the incidence and prevalence of abuse in these populations. Within the boundaries of existing knowledge, it is difficult to determine the limits that beliefs about the probability of sexual exploitation of persons with disability and the consequences of reporting abuse might impose. Our approach to studying the relationship between influential attitudes and subsequent abuse protection or response behaviors recognizes that studies attempting to correlate attitude and behavior experience limited ability to predict from general knowledge and attitudes to subsequent behavior. Conversely, studies that examine beliefs about the probability of an occurrence, its consequences, and the degree to which other people in the social environment would support the behavior had high predictive power. Attention to these issues can enable us to identify critical contingencies affecting those working with persons with disabilities confronting sexual exploitation.

The limitations of this study include our dependence on an available sample of persons interested and committed to the care of persons with disability at risk for sexual exploitation. Generalizations to other populations must be drawn with caution. Further, the study's methodology is limited to the participants' self-reported extent of professional training, responsibility, and concern, rather than their observed behavior in dealing with the professional responsibilities. In addition, the study depends on a paper-and-pencil methodology, presenting written descriptions of the populations and situations described. This might have influenced the particular configuration of disabilities (i.e., cognitive impairments) that featured most consistently and prominently in the assessment of populations most at risk. In contrast, Goffman posited that the extent and visibility of disabilities must determine responses.(7) If the visibility of a disability drives responses, does the prominence the raters in this study gave to cognitive disabilities suggest that the raters assume cognitive disabilities are visible to the beholder? Alternatively, corroboration for the finding that, as in our study, other factors might mediate response to disability occurs in studies of persons intimately familiar with the experience people with disability-persons with disability. These studies have found that characteristics defining power and dependence adopted by persons with disabilities draw on other variables, notably education, gender, marital status, age and local-cosmopolitan orientation.(32)

This study, then, might best be seen as providing insights into the thought- 
ful, best intentions of health care professionals concerned for the welfare of persons with disability. The self-portrait these professionals create is one of personal commitment to providing sympathetic care. What is disturbing about these portraits, however, is what is missed or misperceived.

Respondents tended to qualify their self-reported expertise in sexual abuse prevention. This occurred despite the limited knowledge of the formal expectations for competency in sexual health education and sexual exploitation prevention.(33) The implications of this finding suggest that these professionals assume that greater expertise is available and needed.

A further note of encouragement can be drawn from the health care professionals' avowed sensitivity to the emotional concerns persons with disabilities might encounter. Despite the concerns in the literature about the emotional detachment of health care professionals from their patients in general, and, in particular, those with stigmatized conditions, this study found that the health care professionals displayed considerable concern about the emotional state of patients with disability who might have been sexually exploited. Should we then infer that concerns about professionals' failure to deal with problems emerging in the care of the disabled are not warranted?

The caveats for rejecting this conclusion include the institutional dynamics attendant to stigma and the constraints posed in the social context of professional medical care. These concepts are embodied in the haunting refrain of "credibility" that emerged in the analysis of health care professionals' projections of "worst" and "best" outcome scenarios. Health care professionals tended to limit the characterization of the sequelae of sexual exploitation to issues of credibility and emotional reassurance of the patient, rather than inspiring consideration of the need for empowering action of the health care professional and patient on the larger social environment.

Given the consistency of responses that failed to recognize the risk posed to some populations of persons with difficulty, we would be most concerned with the limited attention that might be given to preventing or detecting instances of abuse among these populations. We would see the need for this concern as well in settings in which many different kinds of disability were represented. We stress the need for interdisciplinary reviews in clinical settings, so that health care professionals can recognize patterns of abuse potential in seemingly disparate populations.

The implications for the immediate future include responding to the need the professional community reported for greater training in sexual health and sexual abuse prevention. Since detecting instances of abuse was considered so consistently the greatest difficulty facing professionals, it would be critical for this training to examine ways in which perception of vulnerability affects ability to detect exploitation. This would be particularly germane in dealing with populations whom the professional considers to be at less risk. The implicit 
bias in perceiving greater risk for those with impaired cognitive functions would seem to overlook the clear vulnerability of the physically and learning disabled.

Training and research should also address the particular problems of dealing with abuse cases in which family members and health care professionals are involved. In contrast to the respondents caution in evaluating the adequacy of their own professional training in sexual abuse prevention, respondents posited considerable confidence in their ability to report instances of abuse in which the perpetrator was a health care professional. Is the assumption that dealing with an exploitative health care professional poses no greater difficulty warranted?

We contend that this assumption is unwarranted and potentially dangerous. Studies emphasizing the need for "good attitudes" of the health care professional can convey the assumption that, because someone is a professional, they will have good intentions and that, if one has good intentions, their actions will be ethical. These assumptions constitute errors in logic.

Our further caution is that, in situations where professionals consider that they can make limited impact, failing to perceive problems saves work. As Fox notes, it is "functional" for professionals to perceive greater uncertainty about the presence of issues that would require them to confront unpleasant and demanding situations. For example, a clinician who emphasizes the uncertainty of clinical detection measures can rationalize more readily avoiding the work of informing patients about a diagnosis of a terminal disease. In this study, professionals attributed the greatest difficulty to the task of detecting instances of abuse. In contrast, they reported considerable confidence in their ability to $r e$ port these issues, if only, somehow, they could be detected. Respondents reported such confidence even in the challenging situation in which the perpetrator was another health professional. This perception minimizes the complexity in gauging collegial relationships and actions. Among the interdependent-but not equally powerful or accountable - members of the health care team, the potential to monitor, observe, or document inappropriate actions are considerably constrained. A further subtle deterrent to perceiving instances of abuse can be inferred from the pattern of responses in which the-respondents acknowledged how difficult it would be for them to achieve satisfactory follow-up for persons with disabilities who have been exploited.

Methods for which the professional can assess follow-up that respect the dignity and vulnerability of the persons with disabilities need to be shared. We urge that these measures emphasize active measures institutions take to prevent exploitation and examine its potential occurrence. Cole(34) indicates one way in which this resolve ean be achieved: provide situational definitions of what constitutes vulnerability. Her definition of "how to create a victim" (Table 2) provides a thoughtful means for health care professionals to go beyond "intend- 
Table II. How to Create a Victim

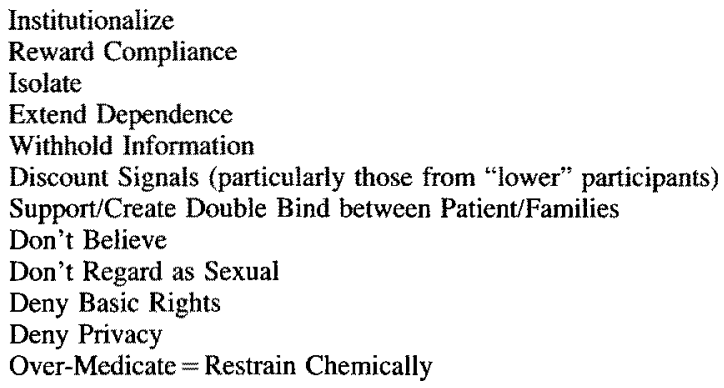

ing to do good." These explicit criteria draw our attention from the--perhaps erroneous and dangerous-assumption that the institution of medicine will avoid the dynamics that have engendered the tragic victimization of the vulnerable in other institutions.

The analytic perspectives we have adopted here reflect the resolve that, for describing and analyzing professional judgments in medicine, we need to be able to characterize the way people make sense of and act upon a world of "booming, buzzing confusion."(35) Noting the consistent emergence of situational effects in studies of competence in the health professions, LaDuca(36) proposes we define competence in health professions from "a relational model in which competence is seen as the aggregated adaptations of practitioners to the set of special social circumstances that obtain within the situational boundaries of their profession." We suggest that persons with disability and the professionals who work with them are best served by approaches that recognize this social context.

\section{ACKNOWLEDGMENTS}

This research was conducted in the context of a conference, supported by the Kenny Rehabilitation Foundation of Michigan and the Department of Physical Medicine and Rehabilitation, on sexual exploitation of persons with disabilities. This conference was held at the University of Michigan Medical Center on September 26-27, 1988. A preliminary version of this paper was presented as "Tea and Sympathy: The Limits Implicit in Health Care Workers' Perceptions of the Impact of Abuse of Persons with Disabilities" at the 1989 Meeting of the Society for the Scientific Study of Sex. 


\section{REFERENCES}

1. Light RJ, Pillemer DB. Summing up: the science of reviewing research. Cambridge, Massachusetts: Harvard University Press. 1984.

2. In sociology, an institution is defined as an organized way of delivering an essential human service. Examples of institutions are the family, religion, education, government, and medicine.

3. Starr P. The social transformation of American medicine: the rise of a sovereign profession and the making of a vast industry. New York: Basic Books. 1982.

4. Quoted in Deutsch, Albert. The mentally ill in America: a history of their care and treatment from colonial times. New York: Columbia University Press. 1949.

5. Durant W. The story of civilization II: the life of Greece. New York: Simon and Schuster. 1939.

6. Fox, R. The evolution of medical uncertainty. Milbank Memorial Find Quarterly/Health and Society. 58(1): 1-49. 1980.

7. Goffman E, Stigma: Notes on the Management of Spoiled Identity. Englewood Cliffs, New Jersey: Prentice-Hall. 1963.

8. MacGregor F, Able T, Byrt A, Laver E, Weissman S. Facial deformities and plastic surgery: a psychosocial study. Springfield, Illinois: Charles C. Thomas. 1953.

9. Anonymous. Sexual assault: a case history. The Spokesman. XIV: 6-7. 1988.

10. Cole provides an overview of programmatic efforts in dealing with sexual abuse in persons with disabilities, highlighting the work of the Seattle Rape Relief's developmental disabilities project.

Cole SS. Facing the challenges of sexual abuse of the disabled. Sexuality and Disability. 7 (3/4): 71-88. 1986.

11. Will GF. For the handicapped, rights but no welcome. Hastings Center Report. 16 (3): 5-8. 1986.

12. Ben-Sira Z. Disability, stress, and readjustment: the function of the professional's latent goals and affective behavior in rehabilitation. Social Science and Medicine. 23 (1): 43-55. 1986.

13. Morgan M, Patrick DL, Charlton JR. Social networks and psychosocial support among disabled people. Social Science and Medicine 19 (5): 489-497. 1984.

14. Colvez A, Robine JM. Problems encountered in using the concepts of impairment, disability, and handicap in a health assessment survey of the elderly in Upper Normandy. Int Rehabil Med. 8 (1): 18-22. 1986.

15. Bury MR. Dilemmas facing patients and providers in disablement. Int Rehabil Med 7 (4): 162-166. 1985.

16. Kazak AE. Families with physically handicapped children: social ecology and family systems. Fam Process 25 (2): 265-281. 1986.

17. Flamer S. Psychological outcomes of rehabilitation: some issues in selection and measurement. Int Rehabil Med 7 (4): 156-160. 1985.

18. Report of the U.S. Preventive Services Task Force. Guide to clinical preventive services: an assessment of the effectiveness of 169 interventions. Baltimore, Maryland: Williams and Wilkins. 1989.

19. Mechanic D. Medical Sociology. New York: Free Press. 1978.

20. Fox R. Training for uncertainty. In The student-physician, ed. R. K. Merton, G. G. Reader, and P.L. Kendall. Cambridge, Massachusetts: Harvard University Press. 1957.

21. Light D. Becoming psychiatrists: the professional transformation of self. New York: Norton. 1980.

22. Gritzer G, Arluke A. The Making of Rehabilitation: a Political Economy of Medical Specialization, 1890-1980. Berkeley: University of California Press. 1985.

23. Cole S. et al. Certification Requirements for Sexologists. American Association of Sex Educators, Counselors, and Therapists. 1980.

24. Albrecht GL, Walker VG, Levy JA. Social distance from the stigmatizes: a test of two theories. Social Science and Medicine 16 (4): 1319-1327. 1982.

25. In organizational research, Etzioni emphasizes the complementary power wielded by those 
with relatively less status (whom he describes as "lower" participants) in complex organizations. Etzioni A. A Comparative Analysis of Complex Organizations. New York: Free Press. 1975.

26. Bogdan R, Taylor S, DeGrandpre B, Haynes S. Let them eat programs: attendants' perspectives and programming on wards in state schools. Journal of Health and Social Behavior. 15: 142-151. 1974.

27. Kutner B. The social psychology of disability. In Rehabilitation Psychology (Edited by W.S. Neff). American Psychological Association. Washington, D.C.

28. English RW. Correlates of stigma towards physically disabled persons. Rehabil Res Pract Rev. 2 (4): 1-15, 1971.

29. Petrie HG. Do you see what I see? The epistemology of interdisciplinary inquiry. Educational Researcher. 5 (2): 9-15. 1976.

30. Goetz J, LeCompte M. Ethnographic research and the problem of data reduction. Anthropology and Education Quarterly. 12, 51-70. 1981.

31. "Intellectual impairment" refers to the cognitive deficits that result from, for example, stroke or traumatic brain injury.

32. May JT, Hill RF. How shall we see them? Perspectives for research with disabled organizations. Social Science and Medicine 19 (6): 603-608. 1984.

33. Cole, SS. Introduction to Special Issue on Abuse. Sexuality and Disability. 9 (3) 1991.

34. Cole SS, Kope SA. How to create a victim. Unpublished manuscript. Cole SS. Overview of sexual development in the life span and sexual exploitation of persons with disability. Institute for the advanced study of human sexuality. 1990. (Film)

35. James W. Principles of Psychology. 1892.

36. LaDuca A. The structure of competence in health professions. Evaluation and the Health Professions. 3 (3): 253-288. 1980. 